\title{
P0015
}

\section{STUDY ON THE RELATIONSHIP BETWEEN PREFERRED ILLUMINANCE AND CORRELATED COLOUR TEMPERATURE OF LED LIGHTING FOR VISUALLY CHALLENGED PEOPLE - FOR FAMILY GATHERING -}

\author{
Michico Iwata
}

DOI 10.25039/x46.2019.PO015

from

CIE x046:2019

\author{
Proceedings \\ of the \\ 29th CIE SESSION
}

Washington D.C., USA, June 14 - 22, 2019

(DOI $10.25039 / \times 46.2019)$

The paper has been presented at the 29th CIE Session, Washington D.C., USA, June 14-22, 2019. It has not been peer-reviewed by CIE.

(C) CIE 2019

All rights reserved. Unless otherwise specified, no part of this publication may be reproduced or utilized in any form or by any means, electronic or mechanical, including photocopying and microfilm, without permission in writing from CIE Central Bureau at the address below. Any mention of organizations or products does not imply endorsement by the CIE.

This paper is made available open access for individual use. However, in all other cases all rights are reserved unless explicit permission is sought from and given by the CIE.

CIE Central Bureau

Babenbergerstrasse 9

A-1010 Vienna

Austria

Tel.: +4317143187

e-mail: ciecb@cie.co.at

www.cie.co.at 


\title{
STUDY ON THE RELATIONSHIP BETWEEN PREFERRED ILLUMINANCE AND CORRELATED COLOUR TEMPERATURE OF LED LIGHTING FOR VISUALLY CHALLENGED PEOPLE - FOR FAMILY GATHERING -

\author{
Iwata, Michico \\ Setsunan University, Neyagawa, Osaka, JAPAN \\ michico@led.setsunan.ac.jp
}

DOI 10.25039/x46.2019.PO015

\begin{abstract}
This research aims to clarify the relationship between the preferred illuminance and correlated colour temperature for activities of family gathering and reading by conducting subjective experiments using dimmable and colour adjustable LED lighting in an experiment room set up in such a way that it resembles a family room. For family gathering, the average values for the visually challenged subjects preferred illuminance and correlated colour temperature were approximately controllable maximum illuminance $300 \mathrm{Ix}$ and $4000 \mathrm{~K}$. In terms of family gathering, there were almost no differences between the young sighted subjects and the visually challenged subjects in illuminance.
\end{abstract}

Keywords: LED Lighting, Visually Challenged, Correlated Colour Temperature, Illuminance.

\section{Introduction}

Diverse activities, including gathering with the family, listening to music, enjoying tea or alcoholic beverages and more, take place in the family room of a house. It is required to appropriately provide pleasant visual environments including visibility of colours and details of related objects for respective activities. While dimmable and colour adjustable LED lighting has become popular and has been actively introduced in residential buildings in recent years, very few researches on dimmable and colour adjustable LED lighting have been conducted so far.

This research aims to clarify the relationship between the preferred illuminance and correlated colour temperature for activities of gathering and reading by conducting subjective experiments using dimmable and colour adjustable LED lighting in an experiment room set up in such a way that it resembles a family room.

\section{Experiments}

\subsection{Experiment room and lighting conditions}

We set up a $3.0 \mathrm{~m}$ (depth) $\times 3.0 \mathrm{~m}$ (width) $\times 2.3 \mathrm{~m}$ (height) experiment room resembling a family room in the dark room (figure 1). The walls and ceiling were covered with white paper and the floor was covered with wood-patterned tile floor mats. Gray (N5) sofas and a brown (7.5YR5/6) table for family gathering were placed in the centre of the room. Indoor plants, writing paper, and a comic book were placed on the table $(0.5 \mathrm{~m}$ height). 


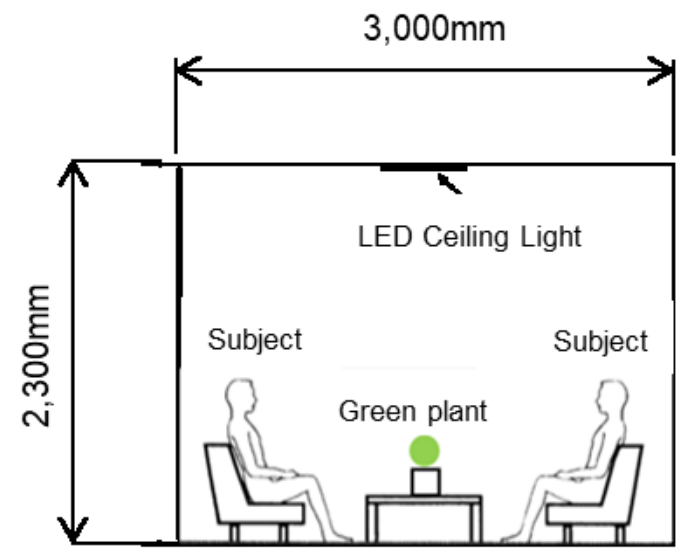

Figure 1 - Experiment space

Dimmable and colour adjustable LED lighting (Toshiba; LEDH95046-LC) was installed on the ceiling and the illuminance and correlated colour temperature were measured at the centre of the table.

The illumination environment was 16 conditions combining the illuminances and the colour temperatures shown in Table 1.

Table 1 - Lighting Conditions

\begin{tabular}{|c|c|}
\hline Illuminance (Ix) & $50,100,200,300$ \\
\hline Correlated color temperature (K) & $3000,4000,5000,6000$ \\
\hline
\end{tabular}

\subsection{Experimental Period and Visually Challenged Subjects}

The experiment was conducted on 31 visually challenged persons (14 males and 17 females) (hereafter referred to as "LV"), from November 13 to December 10, 2018. Distributions of the LV by age groups and disease attributes are shown in Figures 2 and 3, respectively. The authors also conducted an experiment on sighted people ${ }^{1)}$ : 15 male and female students (6 males and 9 females) in their 20's (hereafter referred to as "YG").

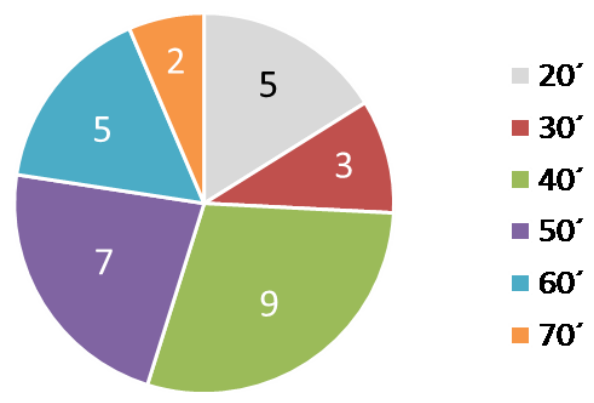

Figure 2 - Age Group Distribution

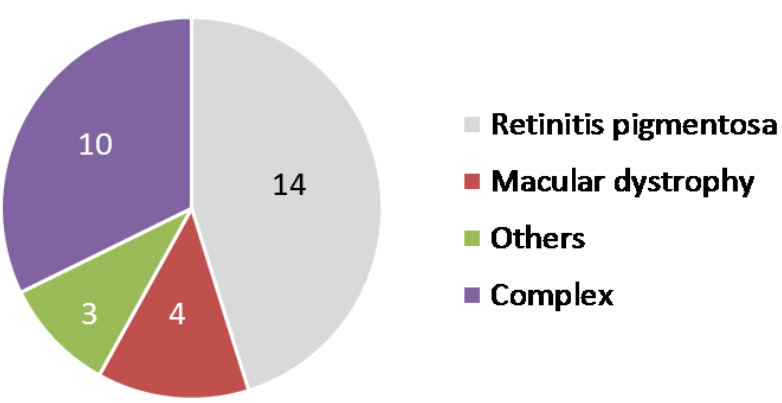

Figure 3 - Disease Distribution

\subsection{Experiment Method}

The experiment consists of two parts: a subjective assessment by Semantic Differential (SD) using adjective pairs (hereafter referred to as "Experiment I"), and an experiment where the subjects adjust both illuminance and colour temperature to their preference (hereafter referred as "Experiment II"). The experiment method is shown in Figure 4. 
Experiment I SD method

Evaluation method

Relax for three minutes, resembling family gatherings

1) An experimenter verbally asks questions in a subjective assessment, and subjects verbally answer questions.

\section{Lighting conditions}

\begin{tabular}{|ll|}
\hline $\begin{array}{l}\text { Correlated color } \\
\text { temperature }\end{array}$ & 4 random conditions \\
\hline Illuminance & 4 conditions from low to high \\
\hline
\end{tabular}

Experiment II Adjustment method

Evaluation method

1) Subjects dim and adjust the color to obtain the proper brightness for family gatherings.

2) Subjects dim and adjust the color to obtain the proper brightness for reading.

Figure 4 - Experiment Method

\section{(1) Experiment I: SD method using adjective pairs}

For family gatherings, a subjective assessment was conducted by Semantic Differential (SD) using adjective pairs on six items regarding the ambience of a room, 3 items regarding the appearance of plants, 3 items regarding human face appearance, and 3 items regarding text appearance. All items were assessed by a seven-stage scale are shown in Table 2, and the seven-stage assessment scale in Figure 5.

In a front room of the experiment room, the experiment method was explained to the subjects under fluorescent lighting with about $4500 \mathrm{~K}$ correlated colour temperature. Illuminance on their face was set to $150 l x$. Texts were printed with black letters in five different sizes $(16,24,40$, 60 , and 72 points) on white copy paper for the experiments, and each subject chose a text that was easiest to read. During this time, the subjects were adapted to the lighting condition in the front room for about three minutes.

Then lighting environments were set for 16 lighting conditions with random correlated colour temperatures. For each correlated colour temperature, illuminance was set ranging from a dark to light condition. For each lighting environment, a seven-stage assessment was conducted using 15 types of adjective pairs described in Table 2 .

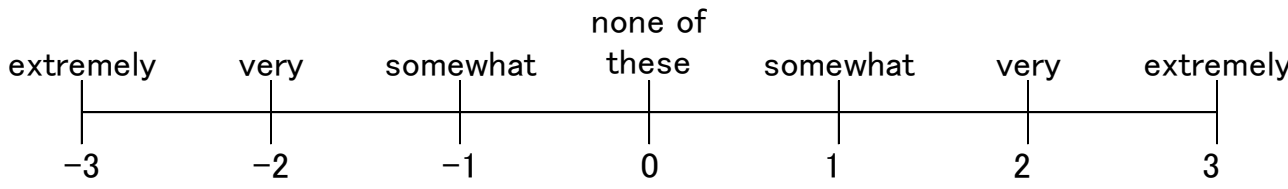

Figure 5 - Evaluation Scale for Seven Stage Assessment 
Table 2 - Adjective Pairs for Evaluations

\begin{tabular}{|c|c|c|}
\hline Room ambience & $\begin{array}{r}\text { Dislike } \\
\text { Cool } \\
\text { Uncomfortable } \\
\text { Unrelaxing } \\
\text { Boring } \\
\text { Dark } \\
\end{array}$ & $\begin{array}{ll}\text { - } & \text { Like } \\
\text { - } & \text { Warm } \\
\text { - } & \text { Comfortable } \\
\text { - } & \text { Relaxing } \\
\text { - } & \text { Enjoyable } \\
\text { - } & \text { Bright } \\
\end{array}$ \\
\hline Plant appearance & $\begin{array}{r}\text { Dull } \\
\text { Unnatural } \\
\text { Hard to see }\end{array}$ & $\begin{array}{ll}- & \text { Vivid } \\
- & \text { Natural } \\
- & \text { Easy to see } \\
\end{array}$ \\
\hline Human face appearance & $\begin{array}{r}\text { Dull } \\
\text { Unnatural } \\
\text { Hard to see }\end{array}$ & $\begin{array}{ll}- & \text { Vivid } \\
- & \text { Natural } \\
- & \text { Easy to see }\end{array}$ \\
\hline Text appearance & $\begin{array}{r}\text { Dark } \\
\text { Uncomfortable } \\
\text { Hard to read }\end{array}$ & $\begin{array}{ll}- & \text { Bright } \\
- & \text { Comfortable } \\
- & \text { Easy to read }\end{array}$ \\
\hline
\end{tabular}

\section{(2) Experiment II: Proper combination of illuminance and correlated colour temperature by an adjustment method}

Experiment II was conducted after Experiment I. Using the ceiling-mounted LED lighting in the experiment room, the correlated colour temperature on the surface of a desk in the middle of the room was set to $4500 \mathrm{~K}$ with $150 \mathrm{Ix}$ illuminance. Subjects were adapted for about three minutes.

For two types of activities (family gathering and reading), the subjects dimmed and adjusted the colour by a remote controller of the ceiling-mounted LED lighting to obtain the proper brightness and correlated colour temperature.

\section{Experimental Result}

\subsection{Experiment I: SD method using adjective pairs}

\section{(1) Ambience evaluation}

\section{1) Ambience evaluation by LV}

Figure 6 shows the profile of ambience evaluation by illuminance. The rating was higher when the illuminance was higher in all items. As a result of an analysis of variation, significant differences between colour temperatures were found in: 50lx for "unrelaxing and relaxing"; 50lx and 100lx for "dislike and like" and "dark and bright"; 50lx, 100lx, and 200lx for "uncomfortable and comfortable" and "boring and enjoyable"; and all illuminances for "cool and warm". 


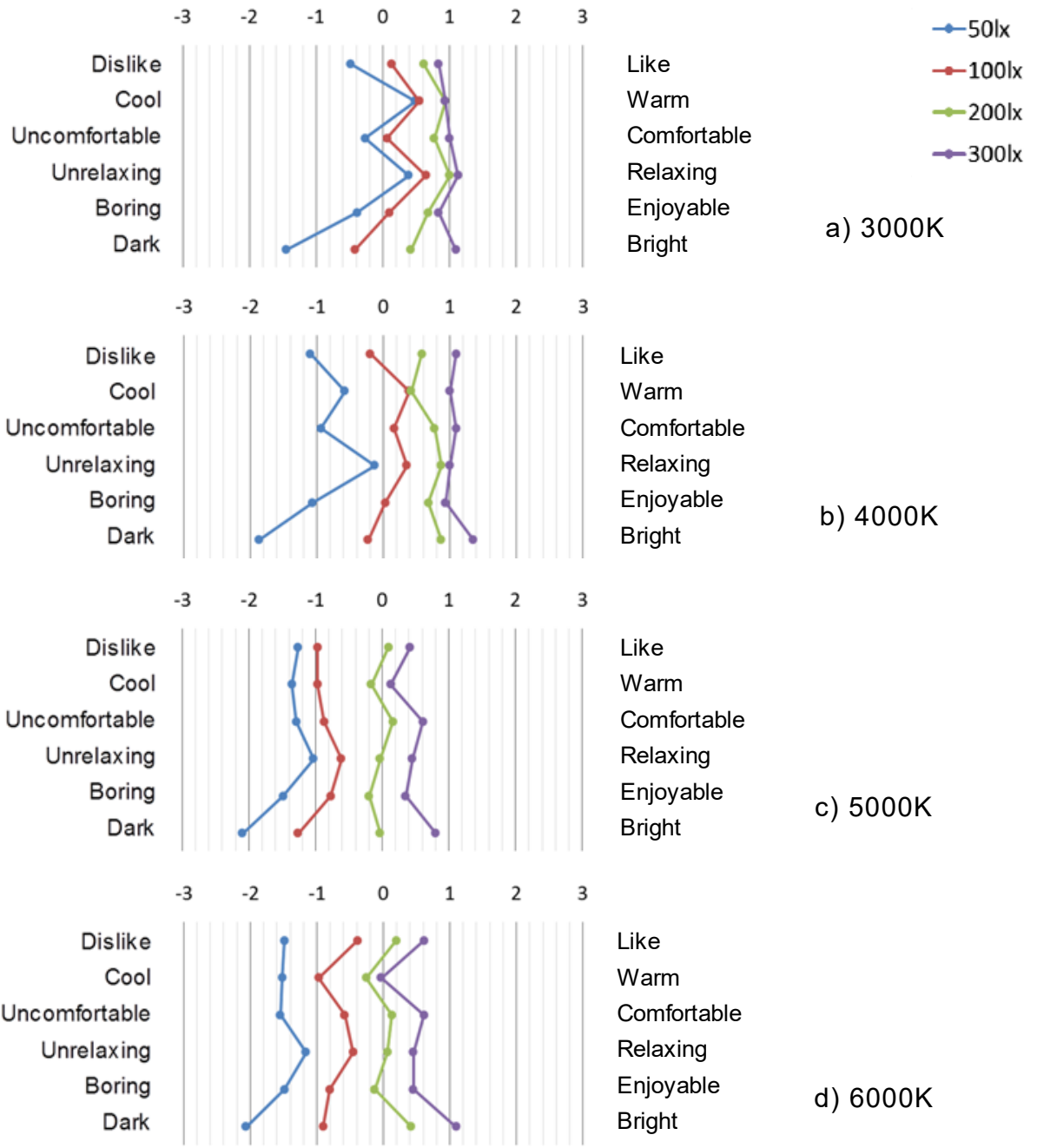

Figure 6 - Profile of Room Ambience Evaluation by LV

\section{2) Comparison with sighted people}

In order to compare the ambience evaluation by LV and sighted people, the relationship between illuminance and rating is shown in Figure 7.

The ratings by sighted people and LV were similar in most items. However, in a low illuminance condition, sighted people had many positive ratings, while LV had many negative ratings. On the other hand, in the "cool and warm" $100 \mathrm{~lx}$ and $4000 \mathrm{~K}$ condition, sighted people had many negative ratings, while LV had many positive ratings. 
Dislike - Like

$3000 \mathrm{~K}$

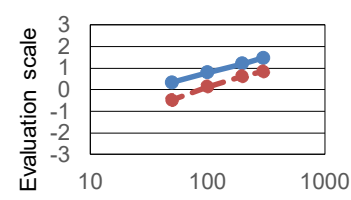

$4000 \mathrm{~K}$

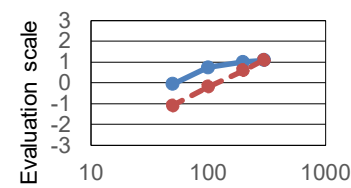

$5000 \mathrm{~K}$

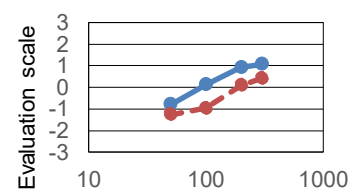

$6000 \mathrm{~K}$

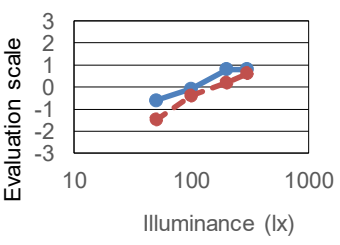

Unrelaxing - Relaxing

$3000 \mathrm{~K}$

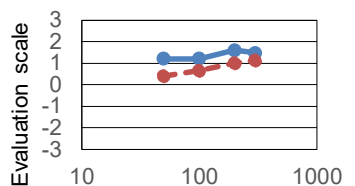

$4000 \mathrm{~K}$

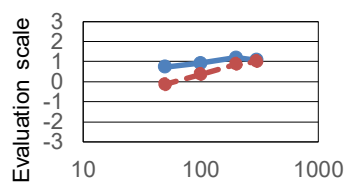

$5000 \mathrm{~K}$

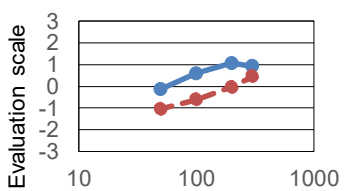

$6000 \mathrm{~K}$

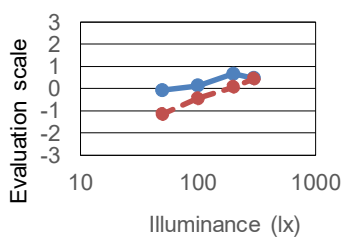

Cool - Warm
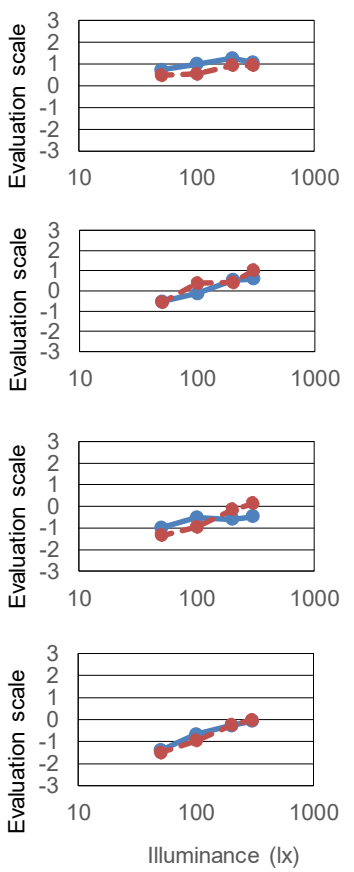

Boring - Enjoyable
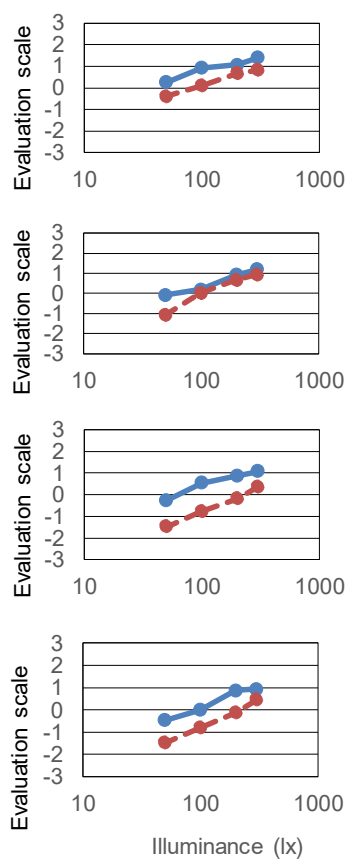

Uncomfortable - Comfortable
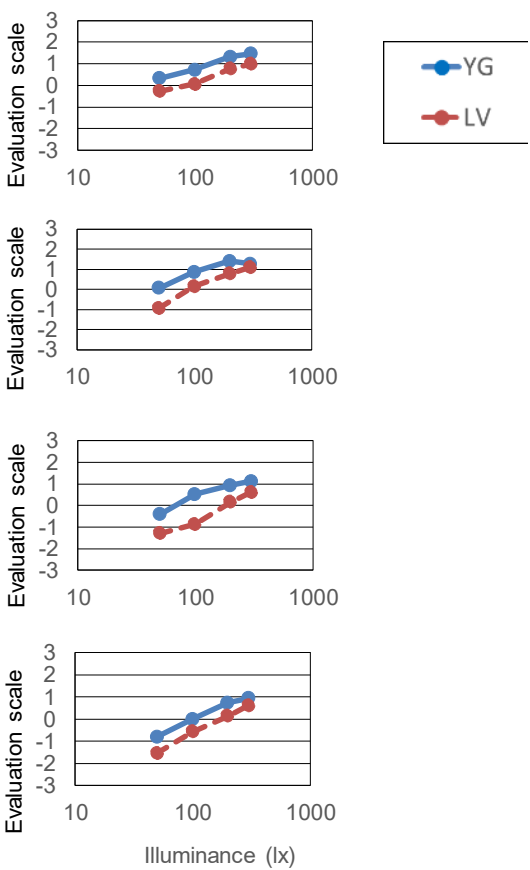

Dark - Bright
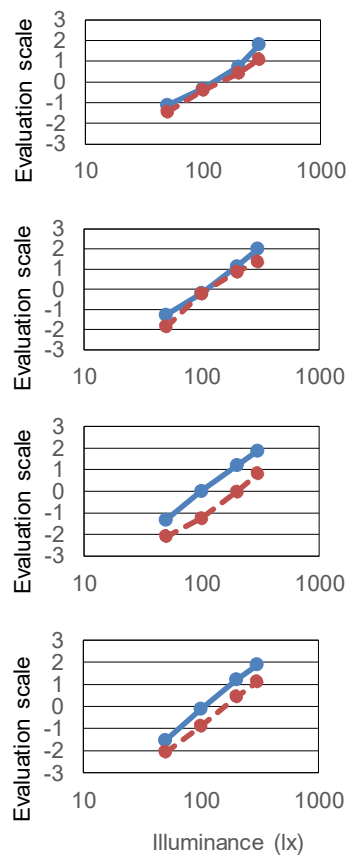

Figure 7 - Comparison of Ambience Evaluation by LV and YG

\section{(2) Evaluation of appearance}

\section{1) Evaluation of appearance by LV}

Figure 8 shows the profile of the appearance rating by illuminance. Except for "unnatural and natural" in the human face appearance, ratings were higher for higher illuminance. In both plant appearance and human face appearance, the highest rank of "dull and vivid" with 50lx was $3000 \mathrm{~K}$, with a significant difference in colour temperature. As for "unnatural and natural" human face appearance, the highest rank was $5000 \mathrm{~K}$ in $100 \mathrm{~lx}$, and $4000 \mathrm{~K}$ in $200 \mathrm{~lx}$ respectively, with significant differences in colour temperature. 


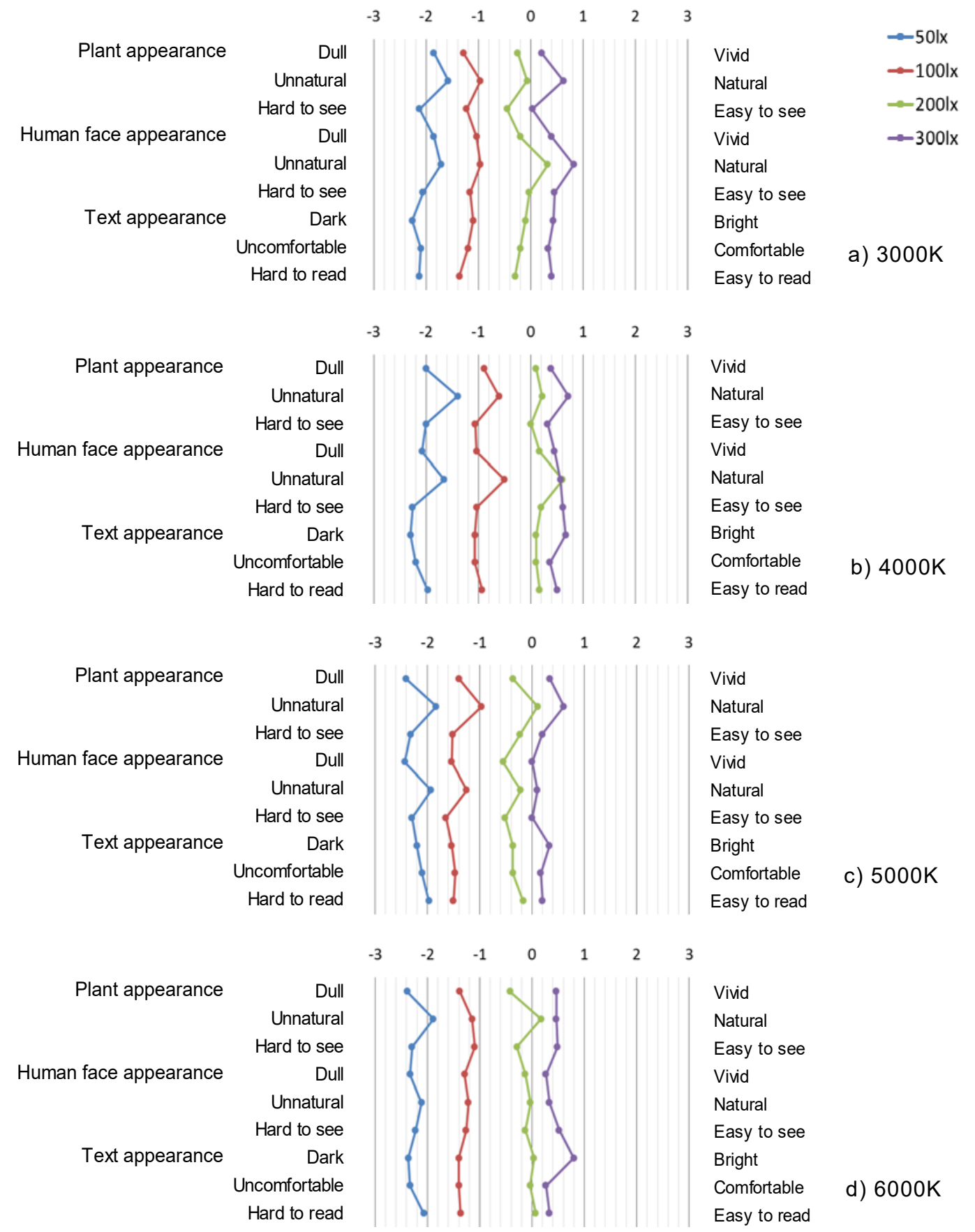

Figure 8 - Profile of Appearance Evaluation by LV

\section{2) Comparison with sighted people}

Among the human face, plants, and text appearance evaluations, the relationships between illuminance and ranking of the human face appearance and text appearance are shown in Figures 9 and 10, in order to compare the appearance rankings by LV and sighted people.

In all items, the human face appearance rankings by sighted people and LV had a clear tendency to increase as illuminance increased. Rankings by LV tended to be negative for $2001 x$ or less for human face appearance, and when less than 300lx for text appearance. 
$3000 \mathrm{~K}$
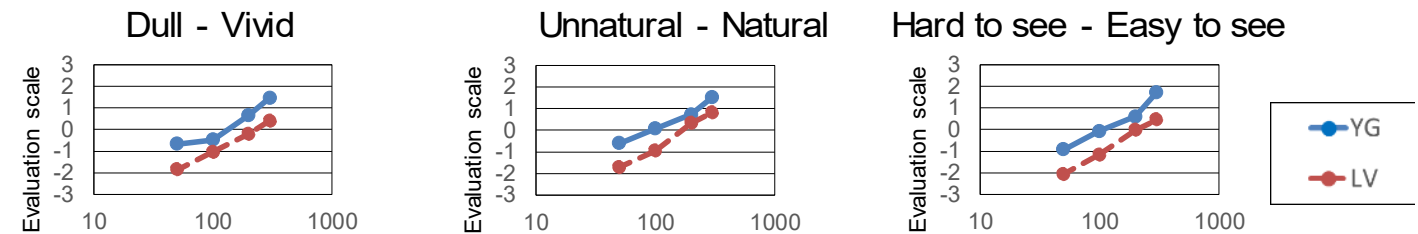

$4000 \mathrm{~K}$
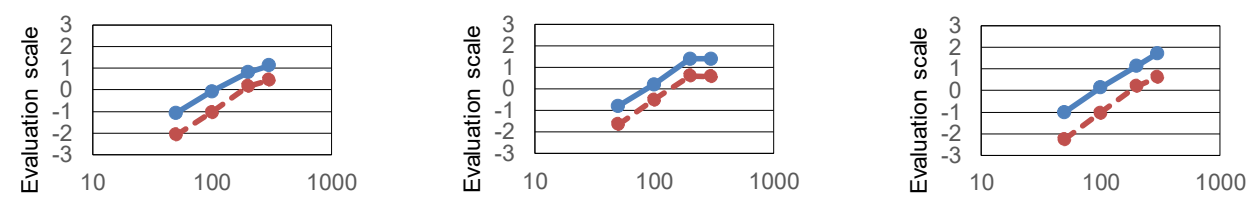

$5000 \mathrm{~K}$
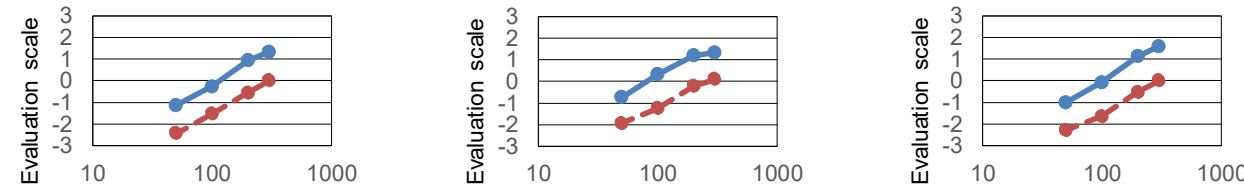

$6000 \mathrm{~K}$
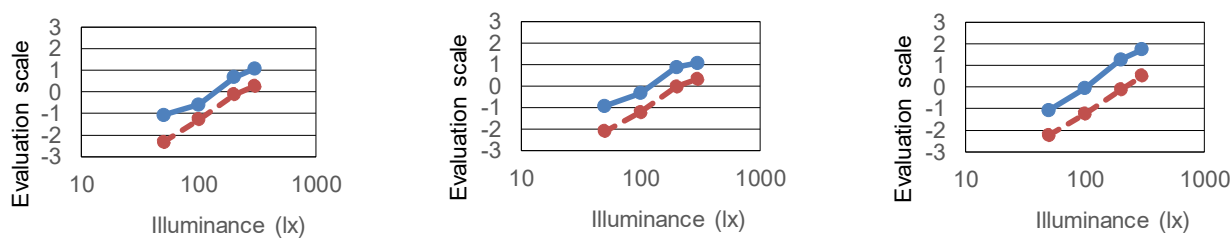

Figure 9 - Comparison of Human Face Appearance Evaluation by LV and YG

Dark - Bright

$3000 \mathrm{~K}$

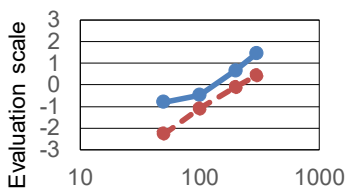

$4000 \mathrm{~K}$

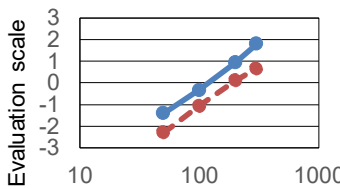

$5000 \mathrm{~K}$

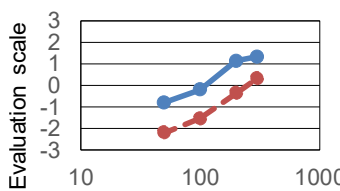

$6000 \mathrm{~K}$

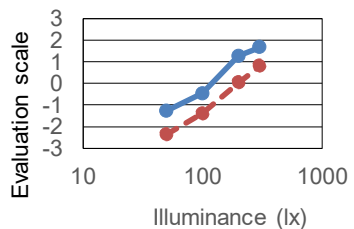

Uncomfortable - Comfortable
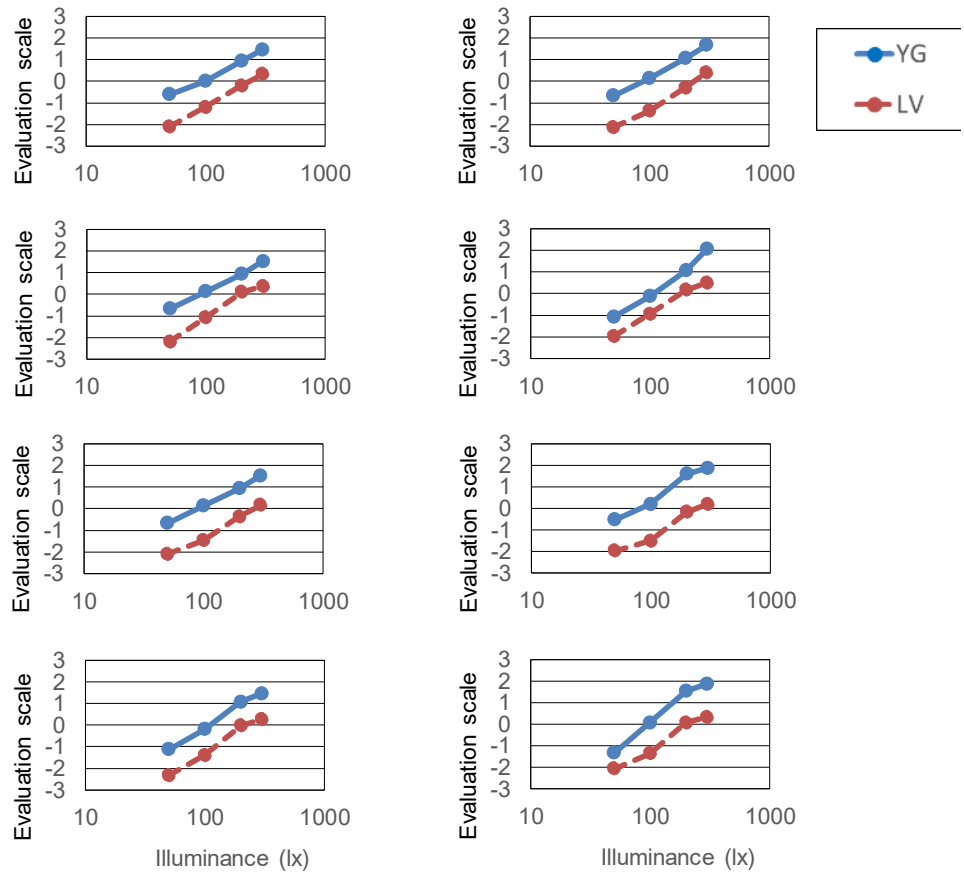

Figure 10 - Comparison of Text Appearance Evaluation by LV and YG 


\subsection{Experiment II: Proper combination of illuminance and correlated colour temperature by an adjustment method}

\section{(1) Family gathering}

\section{1) Case of LV}

Figure 11 shows the relationship between proper illuminance and correlated colour temperature for family gatherings, examined by the adjustment method. An average proper illuminance and colour temperature for family gatherings was $288.91 \mathrm{x}$ and $4032 \mathrm{~K}$, respectively. This result is consistent with the result of Experiment I, in which the ranking was high in $300 \mathrm{~lx}$ and $4000 \mathrm{~K}$. The coefficient of determination in the estimated formula was a rather small 0.1269 .

As for illuminance, the result of sighted people was nearly the same as LV. As for the colour temperature, sighted people were in a narrow range of low colour temperature, while the LV range widely varied from low to high colour temperature.

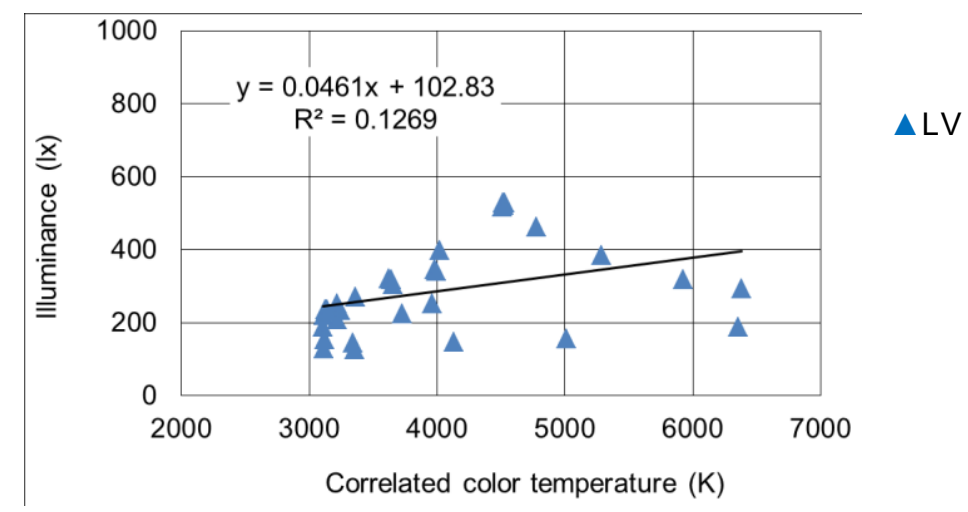

Figure 11 - Relationship between Proper Illuminance and Correlated Colour Temperature for Family Gathering

\section{(2) Reading}

\section{1) Case of LV}

Figure 12 shows the relationship between proper illuminance and correlated colour temperature for reading, examined by the adjustment method. An average proper illuminance and colour temperature were $364.61 \mathrm{x}$ and $4510 \mathrm{~K}$, respectively. Illuminance was about $60 \mathrm{x}$ higher than in Experiment I.

As for illuminance, the result for sighted people was nearly the same as LV. As for the colour temperature, sighted people were in a narrow range, while the LV range widely varied from low to high colour temperature. The coefficient of determination in the estimated formula was a small 0.0698 .

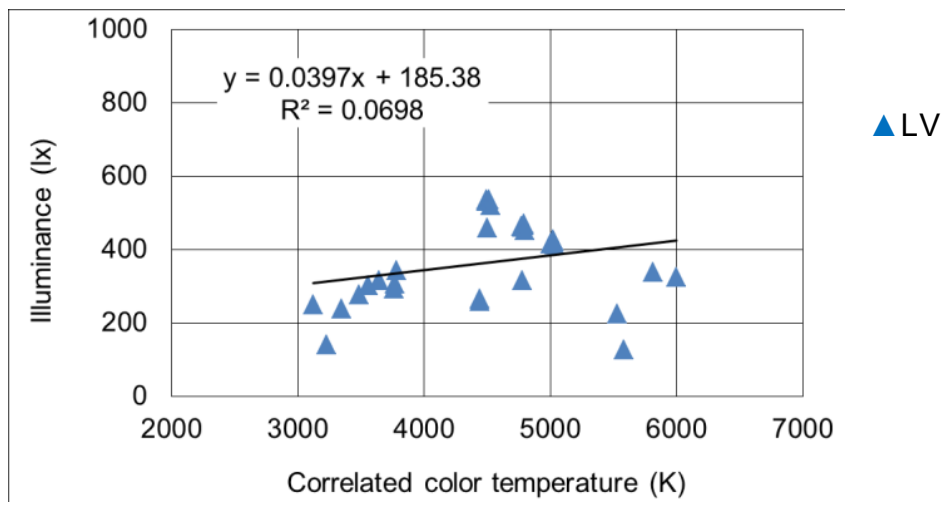

Figure 12 - Relationship between Proper Illuminance and Correlated Colour Temperature for Reading 


\section{(3) Comparison with Kruithof's comfort curve ${ }^{2)}$}

The result of Experiment II is shown in Figures 13 and 14 with the Kruithof's curve. $\boldsymbol{\Delta}$ is for LV and $O$ for sighted people results in this experiment ${ }^{1}$.

As for family gatherings (Figures 13), both LV and sighted people were mostly within the Kruithof's comfort zone. However, three sighted people and six LV preferred a lower illuminance and high colour temperature.

For family gathering, the average values for YG's preferred illuminances and correlated colour temperatures were $248.4 \mathrm{Ix}$ for the illuminance and $3855 \mathrm{~K}$ for the correlated colour temperature.

These evaluated values were mostly situated within the pleasant zone indicated by Kruithof, while slightly shifted toward the low colour temperature and low illuminance. On the other hand, a part of evaluated values was situated in the unpleasant zone toward the low illuminance. The average values for LV's preferred illuminances and correlated colour temperatures were $288.91 \mathrm{x}$ for the illuminance and $4033 \mathrm{~K}$ for the correlated colour temperature. In terms of family gathering, there were almost no differences between YG and LV in both the illuminance and the correlated colour temperature.

As for reading (Figures 14), more points fell within the Kruithof's comfort zone, compared with family gatherings. Ten sighted people and six LV were in a low illuminance and high colour temperature zone.

For reading, the average values for YG's preferred illuminances and correlated colour temperatures were $300.91 \mathrm{x}$ for the illuminance and $5048 \mathrm{~K}$ for the correlated colour temperature. While some of these evaluated values were situated within the pleasant zone indicated by Kruithof, most of the evaluated values were located in the unpleasant zone toward the high colour temperature and low illuminance. The results clearly indicate that Kruithof's curve does not coincide with the evaluated values for reading.

The average values for LV's preferred illuminance and correlated colour temperature were $364.6 \mathrm{~lx}$ for the illuminance and $4510 \mathrm{~K}$ for the correlated colour temperature. The font size of the characters in texts used in LV's evaluation of reading varied individually because different font sizes were used according to the legible font size for each subject. The results indicated that LV prefers a slightly higher illuminance and correlated colour temperature than YG.

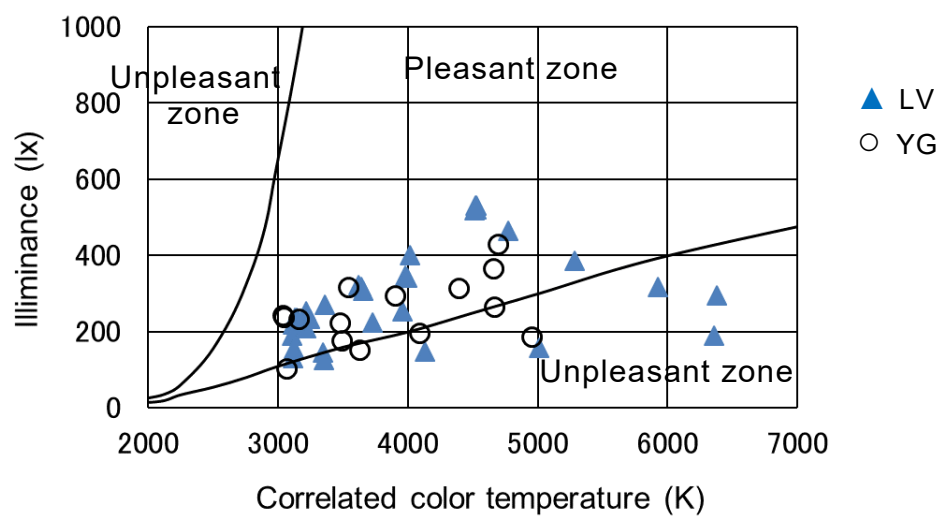

Figure 13 - Comparison of Lighting Requirements for Family Gatherings and Kruithof's Comfort Curve 


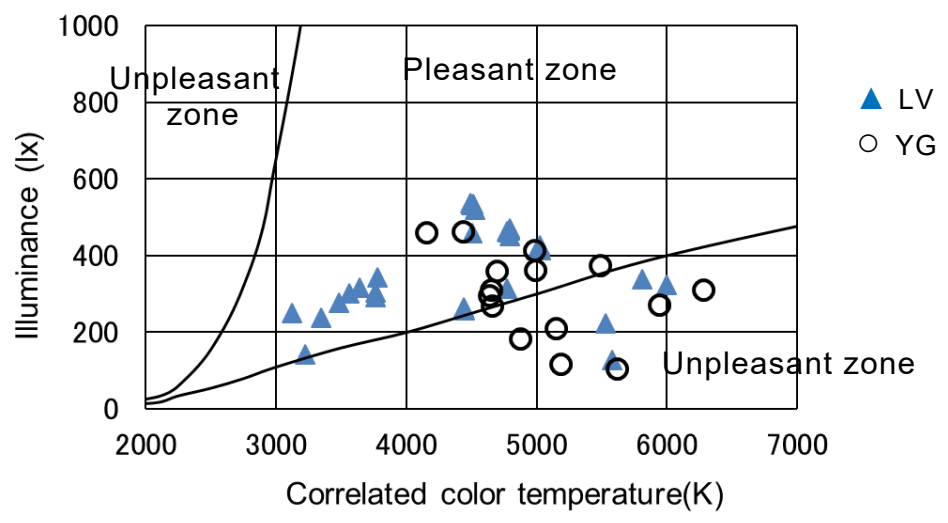

Figure 14 - Comparison of Lighting Requirements for Reading and Kruithof's Comfort Curve

\section{Summary}

Key findings in this study are summarized below.

\section{(1) Results of Experiment I: SD method using adjective pairs}

1) The ambience rating by LV was higher for higher illuminance, but with a wide dispersion.

2) In the ambience rating, the largest difference was seen at $5000 \mathrm{~K}$ between LV and sighted people (lower rating by LV).

3) The rating for relaxation was higher for low colour temperature.

4) Ratings for human face, plants, and text appearance were higher when illuminance increased, with the highest rating at the $4000 \mathrm{~K}$ correlated colour temperature. There was more dispersion with higher illuminance.

5) Ratings by LV were lower than those by sighted people. In particular, at low illuminance, LV had negative ratings even when sighted people had positive ratings for some items.

\section{(2) Results of Experiment II: Combination of proper illuminance and colour temperature by an adjustment method}

1) Using the adjustment method, LV preferred a wide variety of illuminance and correlated colour temperature settings for family gatherings, and individual differences were observed.

2) As for correlated colour temperature for family gatherings, sighted people preferred a lower colour temperature, while LV preferences widely varied from low to high colour temperatures.

3) For family gatherings, proper illuminance and correlated colour temperature for LV were mostly consistent with the ambience rating in Experiment I. For reading, illuminance was about $60 \mathrm{~lx}$ higher, and correlated colour temperature was about $500 \mathrm{~K}$ higher.

4) Illuminance for reading was nearly equal in LV and sighted people. Correlated colour temperature of LV widely varied from low to high colour temperatures.

5) As a result of a comparison with Kruithof's comfort curve, many points were in the discomfort zone with lower illuminance.

\section{Acknowledgments}

We would like to express our gratitude to the people who kindly participated as subjects in our experiments. We would also like to thank several graduates of Setsunan University, Ryuta Matsumoto (2017 graduate), Kaede Ishida, Ryota Kawamoto, Kazunori Miura and Sayumi Oba 
(2018 graduates), for their dedicated contributions to the collection and organisation of data for this research.

\section{References}

1) MIURA Kazunori, IWATA Michico and MATSUMOTO Ryuta. 2018. Examination of Comfortability in Family Rooms Using Dimmable and Colour Adjustable LED Lighting. Proceedings of Annual Conference of the Illuminating Engineering Institute of Japan.

2) KRUITHOF A.A. 1941. Tubular luminescence lamps for general illumination. Philips Technical Review 6, pp.65-96. 